\title{
Growth hormone treatment of premature ovarian failure in a mouse model via stimulation of the Notch-1 signaling pathway
}

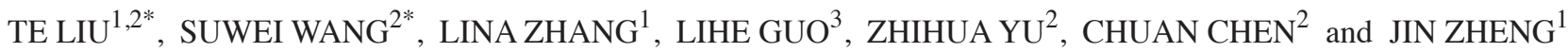 \\ ${ }^{1}$ Department of Gynecology; ${ }^{2}$ Shanghai Geriatric Institute of Chinese Medicine, Longhua Hospital, \\ Shanghai University of Traditional Chinese Medicine; ${ }^{3}$ Institute of Biochemistry and Cell Biology, \\ Shanghai Institute for Biological Sciences, Chinese Academy of Sciences, Shanghai 200031, P.R. China
}

Received January 21, 2015; Accepted March 3, 2016

DOI: $10.3892 /$ etm.2016.3326

\begin{abstract}
Premature ovarian failure (POF) is a condition affecting $1 \%$ of women in the general population, causing amenorrhea, hypergonadotropism and hypoestrogenism before the age of 40. Currently, POF cannot be reversed and, although treatments are available, there is an urgent need for improved treatment strategies. Growth hormone $(\mathrm{GH})$ is a pleiotropic hormone that affects a broad spectrum of physiological functions, from carbohydrate and lipid metabolism to the immune response. $\mathrm{GH}$ has previously been used to treat POF in non-transgenic preclinical trials, but the biochemical mechanism underlying these effects are unclear. In the present study, a mouse model of POF was generated using cyclophosphamide. Treatment of POF mice with recombinant mouse growth hormone $(\mathrm{rmGH})$ was revealed to markedly reduce POF histopathology in ovarian tissue, relieve ovarian granulosa cell injury, reduce the number of atretic follicles and significantly increase the number of mature oocytes. Furthermore, an enzyme-linked immunosorbent assay revealed that plasma estradiol levels increased and plasma follicle stimulating hormone levels decreased with time in a group of mice treated with a medium dose of $\mathrm{rmGH}(0.8 \mathrm{mg} / \mathrm{kg})$ when compared with the POF model group $(\mathrm{P}<0.05)$. In addition, reverse transcription-quantitative polymerase chain reaction and immunohistochemical analysis demonstrated elevated levels
\end{abstract}

Correspondence to: Professor Jin Zheng, Department of Gynecology, Longhua Hospital, Shanghai University of Traditional Chinese Medicine, 725 Wanpin Road, Shanghai 200031, P.R. China E-mail: jinzheng2013@126.com

Professor Chuan Chen, Shanghai Geriatric Institute of Chinese Medicine, Longhua Hospital, Shanghai University of Traditional Chinese Medicine, 365 Xiangyang Road, Shanghai 200031, P.R. China

E-mail:ch9453@126.com

*Contributed equally

Key words: premature ovarian failure, mouse model of disease, growth hormone, notch-1 signaling pathway, hormone therapy of Notch-1 signaling pathway factors (Notch1, CBF1, and HES1) in wild-type mice and those treated with medium and high doses of rmGH, but not in those treated with low doses of rmGH. In conclusion, GH may promote ovarian tissue repair, estrogen release and oocyte maturation via activation of the Notch-1 signaling pathway in ovarian tissue.

\section{Introduction}

Premature ovarian failure (POF) is a condition that causes amenorrhea and hypergonadotropic hypoestrogenism before the age of 40 (1-5). POF affects $1 \%$ of women in the general population, but its prevalence is steadily increasing (1-5). Patients with POF demonstrate a number of characteristic symptoms, as follows: i) Primary or secondary amenorrhea $(2,6-8)$; ii) intermittent or chronic hypoestrogenism $(2,6)$; and iii) hypergonadotropism $(7,8)$. Furthermore, the age of patients at the time of onset is typically under 40 years of age (3-6). In a number of reports describing patients with POF, laparoscopy has revealed an absence of developing follicles, and ovarian biopsies have demonstrated a network of connective tissue interspersed with fibroblasts. Previous studies have reported that the uterus and vaginal mucosa in patients with POF undergo atrophy due to estrogen understimulation as a result of inactive ovaries $(4,9)$. Currently, POF is irreversible and, although treatments are available, drugs to treat POF are very limited; there are no particularly effective treatments and drugs. Hormonal therapy and in vitro fertilization methods are available to help patients with POF conceive, but there is an urgent requirement for improved treatment strategies $(5-7,9)$.

Growth hormone $(\mathrm{GH})$ is a pleiotropic hormone that affects a broad spectrum of physiological functions, from carbohydrate and lipid metabolism to immune response (10-16). Several previous studies have used GH to treat autoimmune diseases and POF. For example, Rojanathammanee et al (14) reported that $\mathrm{GH}$ alters the glutathione S-transferase and mitochondrial thioredoxin systems in long-living Ames dwarf mice. Villares et al (16) used GH to treat type 1 diabetes, demonstrating that it prevented the development of diabetes by a mechanism involving specific $\mathrm{GH}$-mediated effects on islet $\beta$-cells, $\mathrm{T}_{\mathrm{h}} 17 / \mathrm{T}_{\mathrm{h}} 1$ plasticity, M1/M2 macrophage differentiation and $\mathrm{T}_{\mathrm{reg}}$ cell function. Visser et al (11) reported that serum anti-Müllerian hormone levels correlated with 
karyotype, pubertal development, luteinizing hormone and follicle-stimulating hormone (FSH), and is detected at higher levels in patients with Turner syndrome undergoing $\mathrm{GH}$ therapy. Furthermore, Hartmann et al (12) evaluated the effects of oral hormone replacement therapy (HRT) on body weight, insulin-like growth factor 1 (IGF-1) levels and GH response to exogenous GnRH in women with POF. This previous study revealed that women with POF who were not treated with HRT had significantly higher IGF-1 levels, compared with women with POF treated with HRT, which reduced during HRT; however, the body weight of these patients remained stable (12). Numerous studies are beginning to generate and characterize a number of $\mathrm{GH}$-encoding transgenes in mice, expressing factors such as ovine $\mathrm{GH}$, human $\mathrm{GH}$ and bovine GH $(11-13,16)$. Although GH has been used in preclinical trials to treat POF, the mechanisms underlying its activity in the alleviation of POF are poorly understood.

The Notch signaling pathway has critical roles in the development and homeostasis of tissues by regulating cell fate, proliferation, differentiation and apoptosis, and in stem cell self-renewal $(17,18)$. The Notch proteins are a family of evolutionarily conserved receptors that regulate cell fate (17-22). These Notch receptors are activated following direct contact with their ligands, which are expressed on adjacent cells $(18,19)$. In mammals, there are four Notch receptors (NOTCH1-NOTCH4) and five ligands (Jagged-1 and -2 and delta-like protein 1,3 , and 4) $(18,20)$. NOTCH receptors have extracellular, transmembrane and intracellular domains $(18,19)$. Upon ligand binding, the NOTCH intracellular domain (NICD) of the receptor is cleaved by $\gamma$-secretase and translocates to the nucleus, where it associates with the recombination signal-binding protein $\mathrm{j \kappa}(\mathrm{RBPj \kappa})(16,17,20)$. $\mathrm{RBPj \kappa}$ is a key transcription factor in the canonical Notch signaling pathway, and acts downstream of all four NOTCH receptors (19-21). Within the nucleus, NICD forms a large transcriptional activator complex with $\mathrm{RBPj \kappa /CBF} 1$ and Mastermind (19-21). This transcriptional complex then activates the transcription of target genes such as hairy/enhancer of split (Hes) and Hes-associated with YRPW motif, two proteins of the basic helix-loop-helix gene families $(21,22)$. A previous study has demonstrated that the Notch/Hes-1 signaling pathway controls the proliferation of intestinal immature progenitor cells (21). A number of previous studies have indicated that Notch also works with other transcription factors to regulate the expression of its target genes such as cyclin D1, B cell lymphoma 2 and Survivin (16-19,21,22). Furthermore, Notch-1 overexpression has been reported to inhibit apoptosis in numerous types of human cancer, suggesting that it has potential as a therapeutic target (19-22).

The current study aimed to determine whether recombinant $\mathrm{GH}$ can be used as a treatment of POF, and to investigate whether the therapeutic activity of GH is associated with the activation of the Notch-1 signaling pathway.

\section{Materials and methods}

Generation of a mouse model of POF and treatment with recombinant mouse growth hormone ( $\mathrm{rmGH}$ ). Female C57BL/6 mice $(n=72)$ at 4-5 weeks of age, $20 \mathrm{~g}$ weight, were obtained from the Animal Research Center, Longhua Hospital
(Shanghai, China). The present study received ethical approval from the Animal Ethics Committee of the Shanghai University of Traditional Chinese Medicine, in compliance with the Experimental Animal Regulations of the National Science and Technology Commission, China. A total of 3-4 mice per cage were maintained for 14 days in a temperature-controlled environment under $12 \mathrm{~h}$ light-dark cycles with ad libitum access to food and water as previously described (23). To induce POF, mice were administered a single intraperitoneal injection of $70 \mathrm{mg} / \mathrm{kg}$ cyclophosphamide (Sigma-Aldrich, St. Louis, MO, USA) at 7 weeks of age. The animals were divided into control and experimental groups as follows: i) An untreated control group (wild-type; WT) of 12 mice; ii) a negative control group of 12 POF mice receiving a saline injection $(100 \mu \mathrm{l})$; four experimental groups of 12 POF mice, injected daily with $100 \mu \mathrm{l}$ of either iii) 0.4 (low-dose); iv) 0.8 (medium-dose); or v) 1.6 (high-dose) $\mathrm{mg} / \mathrm{kg} \mathrm{rmGH}$ (Sigma-Aldrich), dissolved in saline; vi) 12 POF mice were not administered any treatment. Injections of saline or $\mathrm{rmGH}$ were provided a week after induction of POF, and additional experiments were conducted 21 days after this treatment. At this point, mice were sacrificed by cervical dislocation.

Enzyme-linked immunosorbent assay (ELISA). Mouse blood plasma (100 $\mu \mathrm{l})$ was obtained by mouse retro-orbital blood collection (23), centrifuged at $453 \mathrm{x} \mathrm{g}$ at $4^{\circ} \mathrm{C}$ for $10 \mathrm{~min}$, and the supernatant was collected. The mouse estradiol $\left(\mathrm{E}_{2}\right)$ and FSH ELISA kit (cat. nos. 29764 and 29755; Westang Bio, Shanghai, China) was used according to the manufacturer's protocol, in order to determine the levels of $\mathrm{E}_{2}$ or FSH in the mouse blood plasma. Briefly, $100 \mu \mathrm{l}$ of mouse $\mathrm{E}_{2}$ or $\mathrm{FSH}$ antigens standardized to $125-8,000 \mathrm{pg} / \mathrm{ml}$ or $0.156-10 \mathrm{ng} / \mathrm{ml}$, or diluted mouse plasma, were added to the anti-E $\mathrm{E}_{2}$ or FSH antibody-precoated microwells (as appropriate, in the case of the antigens) and incubated for $60 \mathrm{~min}$. Following 3 washes, horseradish peroxidase-conjugated detection antibodies were added, followed by the substrate solution (Westang Bio). The absorbance of each well was measured at $450 \mathrm{~nm}$ using a microplate reader (BioTek Synergy Mx; BioTek Instruments, Inc., Winooski, VT, USA).

Hematoxylin and eosin staining. Briefly, all ovarian tissue samples were washed 3 times with phosphate-buffered saline (PBS), fixed with 4\% paraformaldehyde (Sigma-Aldrich) for $30 \mathrm{~min}$, dehydrated using a graded series of ethanol, vitrified in xylene and embedded in paraffin (both purchased from Sigma-Aldrich). Following this, serial 6- $\mu \mathrm{m}$ thick sections (Leica RM2235 microtome; Leica Microsystems, Wetzlar, Germany) were made and stained with hematoxylin and eosin (Sigma-Aldrich).

RNA extraction and reverse transcription-quantitative polymerase chain reaction $(R T-q P C R)$ analysis. Total RNA (200 $\mathrm{ng} / \mu \mathrm{l})$ was isolated from mouse ovary tissue from each cell type using TRIzol ${ }^{\circledR}$ (Invitrogen; Thermo Fisher Scientific, Inc., Waltham, MA, USA) according to the manufacturer's protocol. RNA samples were treated with DNase I (2.0 $\mathrm{mU} / \mu 1$; Sigma-Aldrich), quantified and reverse-transcribed into cDNA $(20 \mu \mathrm{l})$ using the ReverTra Ace- $\alpha$ reverse transcription kit (cat. no. FKS-101; Toyobo Co., Ltd., Osaka, 
Japan). RT-qPCR was conducted using a realplex4 real-time PCR detection system (Eppendorf, Hamburg, Germany) with SYBR Green PCR Master mix (Toyobo Co., Ltd.). Primers used for cDNA amplification are listed in Table I. RT-qPCR amplification was performed over 40 cycles of denaturation at $95^{\circ} \mathrm{C}$ for $15 \mathrm{sec}$, annealing at $58^{\circ} \mathrm{C}$ for $45 \mathrm{sec}$ and final elongation at $72^{\circ} \mathrm{C}$ for $42 \mathrm{sec}$ (initial denaturation at $95^{\circ} \mathrm{C}$ for $5 \mathrm{~min}$ for $1 \mathrm{cycle}$, and final elongation at $72^{\circ} \mathrm{C}$ for $10 \mathrm{~min}$ for 1 cycle). Target cDNA levels were then measured using the $2^{-\Delta \Delta \mathrm{Cq}}$ relative quantification method (24). Comparative quantification cycle $\left(\mathrm{C}_{\mathrm{q}}\right)$ values were used to determine relative gene expression, normalized to $18 \mathrm{~S}$ rRNA. For each sample, $\mathrm{C}_{\mathrm{q}}$ values were normalized using the following formula: $\Delta \mathrm{C}_{\mathrm{q}}=\mathrm{C}_{\mathrm{q}}$ experimental genes $-\mathrm{C}_{\mathrm{q}} 18 \mathrm{~S}$ rRNA. Relative expression levels were calculated using the formula: $\Delta \Delta \mathrm{C}_{\mathrm{q}}=\Delta \mathrm{C}_{\mathrm{q}}$ all groups $-\Delta \mathrm{C}_{\mathrm{q}}$ untreated control group.

Immunohistochemistry. Immunohistochemical analysis was performed as previously described $(23,25)$. Briefly, all ovarian tissue samples were washed 3 times with PBS, fixed with $4 \%$ paraformaldehyde for $30 \mathrm{~min}$, dehydrated through a graded series of ethanol, vitrified in xylene and embedded in paraffin. Subsequently, serial $6-\mu \mathrm{m}$ thick sections were made, rinsed with $3 \%$ phosphate buffer (Sigma-Aldrich), and subjected to microwave heat repairing. The samples were then incubated with primary antibodies for $45 \mathrm{~min}$ at $37^{\circ} \mathrm{C}$, as follows: Anti-NOTCH-1 (1:1,000 dilution; mouse polyclonal; cat. no. sc-6014); anti-CBF-1 (1:1,000 dilution; mouse polyclonal; cat. no. sc-9417); anti-Hes-1 (1:100 dilution; mouse polyclonal; cat. no. sc-13844); and anti-p53 (1:100 dilution; goat polyclonal; sc-1313) (all Santa Cruz Biotechnology, Inc., Dallas, TX, USA). Horseradish-peroxidase conjugated goat anti-rabbit immunoglobulin G (1:1,000 dilution; sc-2768; Santa Cruz Biotechnology Inc.) was then incubated with samples for $45 \mathrm{~min}$ at $37^{\circ} \mathrm{C}$. Finally, ABC chromogenic reagent (Sigma-Aldrich) was added to aid the visualization of the secondary antibody, in addition to color detection. PBS ( $\mathrm{pH}$ 7.4) was used as a negative control in the place of primary antibody. Five randomly selected fields of view (magnification, x200; Olympus BX43; Olympus Corporation, Tokyo, Japan) were observed for each tissue section and analyzed using IPP software (version 4.0; Intel Corporation, Santa Clara, CA, USA).

Statistical analysis. All data were analyzed using GraphPad Prism version 5.0 (GraphPad Software, Inc., La Jolla, CA, CA, USA). The data in each experiment are reported as the mean \pm standard error, where applicable, and the differences were evaluated for statistical significance with one-way analysis of variance. $\mathrm{P}<0.05$ was considered to represent a statistically significant difference.

\section{Results}

Medium doses of rmGH rescue ovarian weight, hormone secretion and the number of normal follicles in POF mice. At 14 days after injection, the weight of the ovaries in each group was determined (Fig. 1A). A statistically significant difference was not observed in ovarian weight between POF mice $(2.934 \pm 0.257 \mathrm{mg})$, POF mice treated
Table I. Primers used for reverse transcription-quantitative polymerase chain reaction.

\begin{tabular}{ll}
\hline Gene & \multicolumn{1}{c}{ Primer (5'-3') } \\
\hline NOTCH1 & \\
F & CTCCAACTGTGACACCAACCCTG \\
R & TGTAGCCCTGTAGACACTGGCACTC \\
CBF1 & \\
F & GTGGCACTGTTCAATCGCCTTCG \\
R & CAGTCTGCCCGTAATGGATGTAG \\
Hes 1 & \\
F & GAGAAGAGGCGAAGGGCAAGAATAAA \\
R & CAACACGCTCGGGTCTGTGCTGA \\
Ccnd1 & \\
F & TGTGAGGAGCAGAAGTGCGAAGA \\
R & GCCGGATAGAGTTGTCAGTGTAGATGC \\
$18 S$ rRA & \\
F & AGGGGAGAGCGGGTAAGAGA \\
R & GGACAGGACTAGGCGGAACA
\end{tabular}

F, forward; R, reverse; Hes1, hairy/enhancer of split; Ccnd1, cyclin D1; rRNA, ribosomal RNA.

with a low dose of rmGH $(3.939 \pm 0.321 \mathrm{mg})$ and POF mice treated with saline $(3.014 \pm 0.365 \mathrm{mg}) 14$ days after injection. However, ovarian weight in medium-dose $(4.268 \pm 0.405 \mathrm{mg})$ and high-dose groups $(6.545 \pm 0.551 \mathrm{mg})$ was significantly increased when compared with that of the POF model group ( $\mathrm{P}<0.05 ; \mathrm{n}=12$ mice; Fig. $1 \mathrm{~A})$. An ELISA revealed no observably statistically significant difference in plasma $E_{2}$ levels between the POF model group $(64.58 \pm 7.93 \mathrm{pg} / \mathrm{ml})$, the low-dose group $(112.41 \pm 10.15 \mathrm{pg} / \mathrm{ml})$ and the negative control group treated with saline $(72.94 \pm 9.32 \mathrm{pg} / \mathrm{ml})$. Conversely, the plasma $\mathrm{E}_{2}$ levels increased with time in medium-dose $(242.12 \pm 15.39 \mathrm{pg} / \mathrm{ml})$ and high-dose $(463.32 \pm 29.91 \mathrm{pg} / \mathrm{ml})$ groups compared with that of the POF model group $(\mathrm{P}<0.05$; $\mathrm{n}=12$ mice; Fig. 1B). An ELISA also indicated that plasma FSH levels did not appear to vary significantly between the POF model group $(1,351.01 \pm 68.61 \mathrm{pg} / \mathrm{ml})$, the low-dose group $(778.41 \pm 97.48 \mathrm{pg} / \mathrm{ml})$ and the saline-treated group $(1,308.02 \pm 81.14 \mathrm{pg} / \mathrm{ml})$, but decreased significantly with time in the medium-dose group $(618.22 \pm 95.11 \mathrm{pg} / \mathrm{ml})$ compared with the POF model group $(\mathrm{P}<0.05 ; \mathrm{n}=12$ mice; Fig. 1B). Conversely, the plasma FSH levels increased with time in the high-dose group $(3,357.04 \pm 407.81 \mathrm{pg} / \mathrm{ml})$ when compared with the POF model group ( $\mathrm{P}<0.01 ; \mathrm{n}=12$ mice; Fig. 1B).

Following this, the number of normal and atretic ovarian follicles were counted in each group. A statistically significant difference was not identified in the number of normal follicles and atretic follicles between the POF model group $(3 \pm 1$ and $11 \pm 2$, respectively), the low-dose group ( $5 \pm 2$ and $9 \pm 1$, respectively) and the saline-treated group ( $3 \pm 2$ and $11 \pm 2$, respectively). Conversely, the medium-dose $(10 \pm 2$ normal and $4 \pm 1$ atretic follicles) and high-dose ( $6 \pm 2$ normal and $6 \pm 2$ atretic follicles) groups had a lower number of atretic follicles than that observed in the POF model group ( $\mathrm{P}<0.05 ; \mathrm{n}=12$ mice; Fig. $1 \mathrm{C})$. 


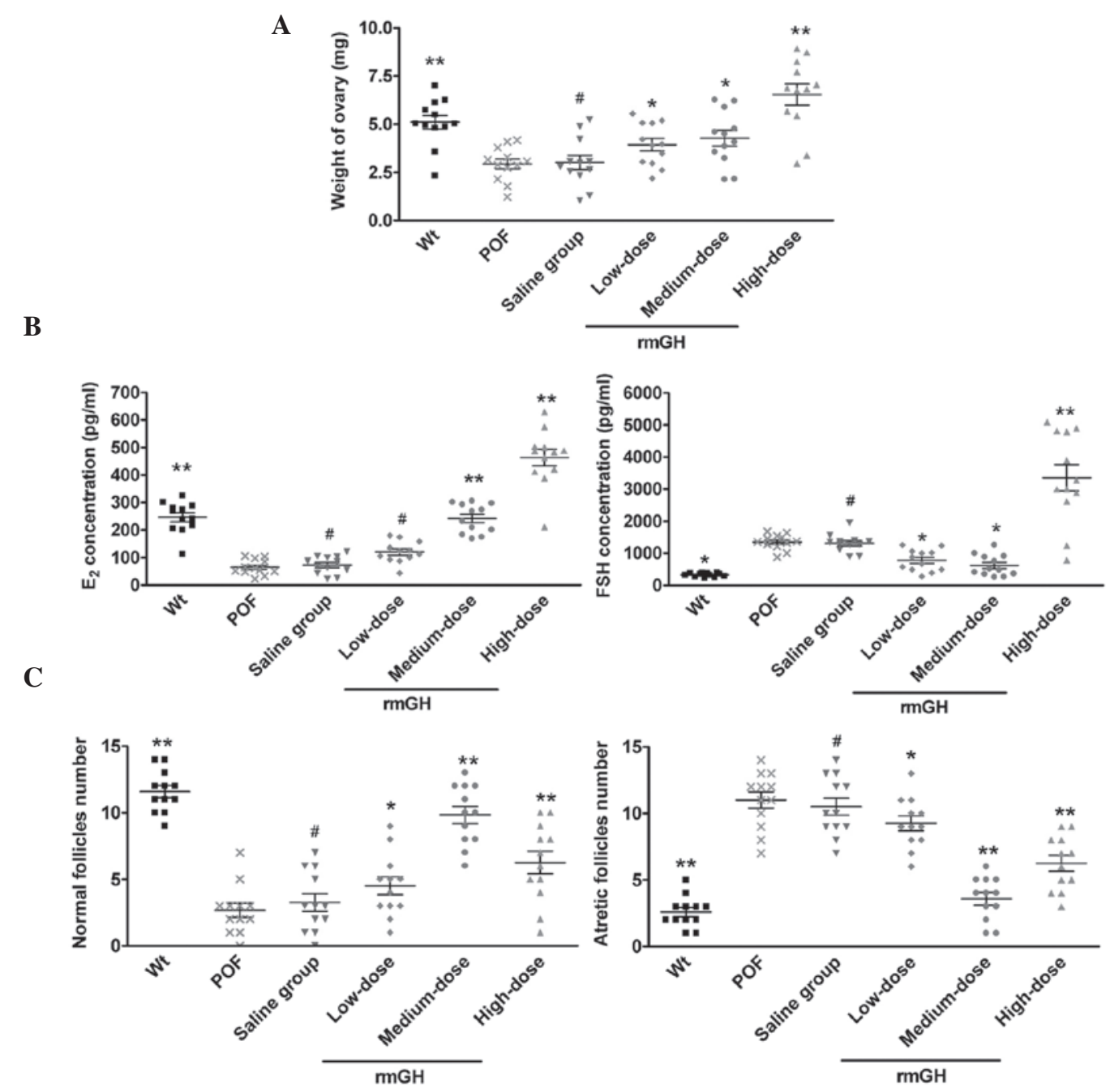

Figure 1. Ovarian weight, plasma $\mathrm{E}_{2}$ and $\mathrm{FSH}$ levels and follicle count following treatment with rmGH or saline, reported as means \pm standard error. (A) Ovarian weight in Wt mice was significantly higher compared with the POF model and saline-treated mice, but no significant difference was identified between medium- and high-dose rmGH-treated POF mice. (B) Plasma $\mathrm{E}_{2}$ levels increased with time in medium-dose and high-dose groups compared with the POF model group. Meanwhile, plasma FSH levels did not appear to vary significantly between the POF model group, the low-dose group and the saline-treated group, but decreased significantly with time in the medium-dose group compared with the POF model group. (C) Follicle counts revealed no statistically significant difference in normal and atretic follicles counts between the POF model and saline-treated groups. Conversely, medium- and high-dose groups had a lower number of atretic follicles than the POF model group. ${ }^{* *} \mathrm{P}<0.01$, vs. the POF group; ${ }^{*} \mathrm{P}<0.05$, vs. the POF group; ${ }^{\sharp} \mathrm{P}>0.05$, vs. the POF group; $\mathrm{n}=12$ mice/group. Wt, wild-type; $\mathrm{POF}$, premature ovarian failure model (untreated group); rmGH, recombinant mouse growth hormone; $\mathrm{E}_{2}$, estradiol; FSH, follicle stimulating hormone.

Hematoxylin and eosin staining revealed that the ovaries of WT mice contained a large number of follicles at all stages of development, ranging from immature to mature (Fig. 2). Conversely, the atrophied ovaries of POF mice consisted primarily of interstitial cells in a fibrous matrix, with a reduced number of follicles at each stage. Furthermore, the ovaries of the POF mice contained an increased number of collapsed oocytes and ovaries were smaller than those of WT mice (Fig. 2). However, following treatment with $\mathrm{rmGH}$, mice exhibited a significant reduction in POF pathology within their ovaries, attenuation of ovarian granulosa cell injury, reduction in the number of atretic follicles and a significant increase in the number of mature oocytes (Fig. 2).

Medium doses of rmGHactivate the Notch-1 signaling pathway in the ovarian granulosa cells of POF mice. At 14 days after injection, the expression levels of the genes involved in the Notch-1 signaling pathway in mouse ovarian granulosa cells were analyzed by RT-qPCR and immunohistochemistry. The RT-qPCR results revealed that the expression levels of Notch1 signaling pathway genes (NOTCH1, Cbfl and Hesl) and cell proliferation factor (Ccnd1; cyclin D1) had decreased in the POF model group compared with the WT group $(\mathrm{P}<0.05$; $\mathrm{n}=12$ mice; Fig. 3). Furthermore, a statistically significant difference was not identified in the expression levels of the Notch-1 signaling pathway genes and the Ccndl between the POF model group, the low-dose group, high-dose group and the saline-treated group $(\mathrm{P}>0.05 ; \mathrm{n}=12$ mice; Fig. 3$)$. However, the expression levels of Notch-1 signaling pathway genes and Ccndl were significantly elevated in the medium-dose group compared with the POF model group $(\mathrm{P}<0.01 ; \mathrm{n}=12$ mice; Fig. 3). Immunohistochemical staining also revealed positive staining for Notch1 signaling pathway factors (Notch1, CBF1, and HES1) in the WT group, medium-dose group and high-dose group, but not in the low-dose or saline-treated groups (Fig. 4). However, p53 staining was positive in the 

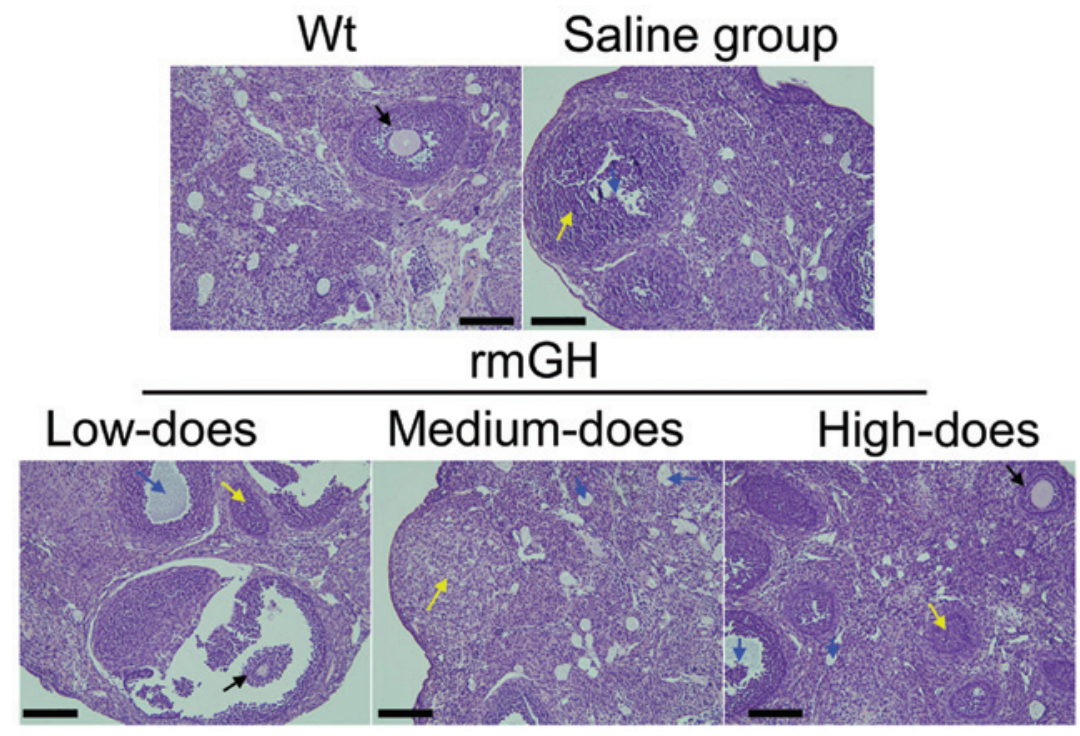

Figure 2. Pathology of mouse ovarian tissue samples following treatment with rmGH or saline, observed using hematoxylin and eosin staining. rmGH treatment significantly improved ovarian tissue pathology, attenuated ovarian granulosa cell injury, reduced the number of atretic follicles and increased the number of mature oocytes in a dose-dependent manner. Magnification, $\mathrm{x} 200$. Scale bar $=200 \mu \mathrm{m}$. Wt, wild-type; rmGH, recombinant mouse growth hormone.

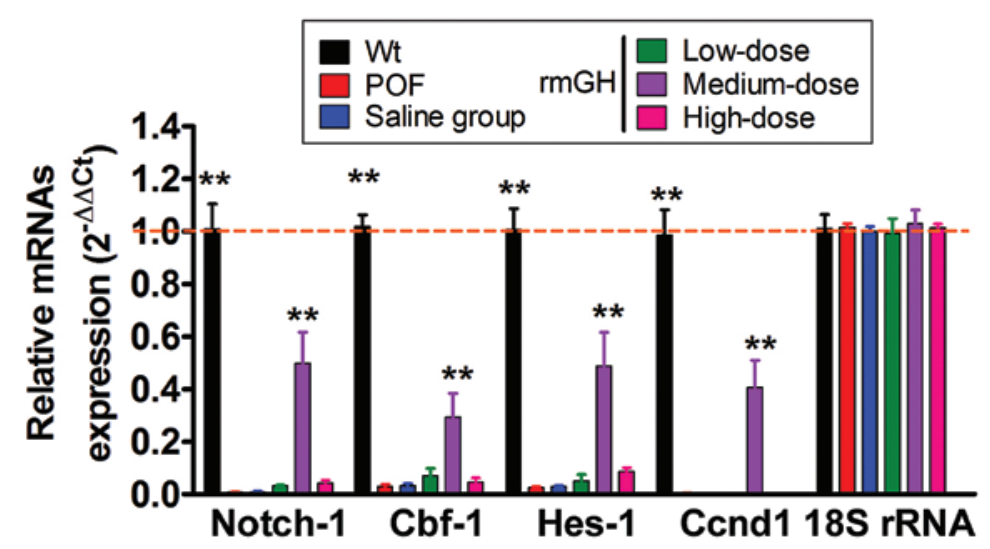

Figure 3. mRNA expression analysis of the Notch1 signaling pathway and cell proliferation factors using reverse transcription-quantitative polymerase chain reaction. Expression levels of Notch1 signaling pathway genes (Notch1, Cbf1, and Hes1) and cell proliferation factor (Ccnd1) were significantly elevated in the medium-dose group compared with the POF model group. ${ }^{* *} \mathrm{P}<0.01$, vs. the POF (untreated) group; $\mathrm{n}=12 \mathrm{mice} /$ group. Wt, wild-type; POF, premature ovarian failure model; rmGH, recombinant mouse growth hormone; Hes1, hairy/enhancer of split; Ccnd1, cyclin D1.

low-dose and saline-treated groups, but not in the WT, medium-dose or high-dose groups (Fig. 4).

\section{Discussion}

POF is an impactful disease and, at present, there is no cure or effective treatment available for POF. Women diagnosed with POF are faced with significant physical and emotional challenges, as this disease can lead to loss of fertility, in addition to osteoporosis and other complications (1-5). GH is a pleiotropic hormone that affects a broad spectrum of physiological functions, from carbohydrate and lipid metabolism to the immune response (10-16). Several previous studies have reported the effective use of $\mathrm{GH}$ to treat autoimmune diseases and POF (14-16). However, the mechanism underlying $\mathrm{GH}$ activity in the treatment of these diseases remains unclear. In the present study, three main questions are addressed: i) Does $\mathrm{rmGH}$ improve hormone release and oocyte maturation in mice exhibiting POF? ii) Is the effect of rmGH on the regulation of hormone levels and oocyte maturation dose-dependent? and iii) What therapeutic mechanism does $\mathrm{rmGH}$ employ to control hormone release and oocyte maturation in POF mice?

Although $\mathrm{E}_{2}$ and FSH hormone levels in POF mice were significantly improved following treatment with medium and high doses of $\mathrm{rmGH}$ treatment, a medium dose of $\mathrm{rmGH}$ was the most effective, leading to significantly increased $\mathrm{E}_{2}$ levels and decreased FSH levels in the peripheral blood of POF mice. High doses of rmGH also elevated $\mathrm{E}_{2}$ levels in peripheral blood, although FSH levels significantly increased from that observed in the medium-dose group. It may be speculated that high doses of GH stimulate the body to release hormones in a non-specific manner, causing this increase in FSH. GH was also reported to stimulate oocyte maturation and reduce the number of atretic follicles in a dose-dependent manner; these effects were only observed in 


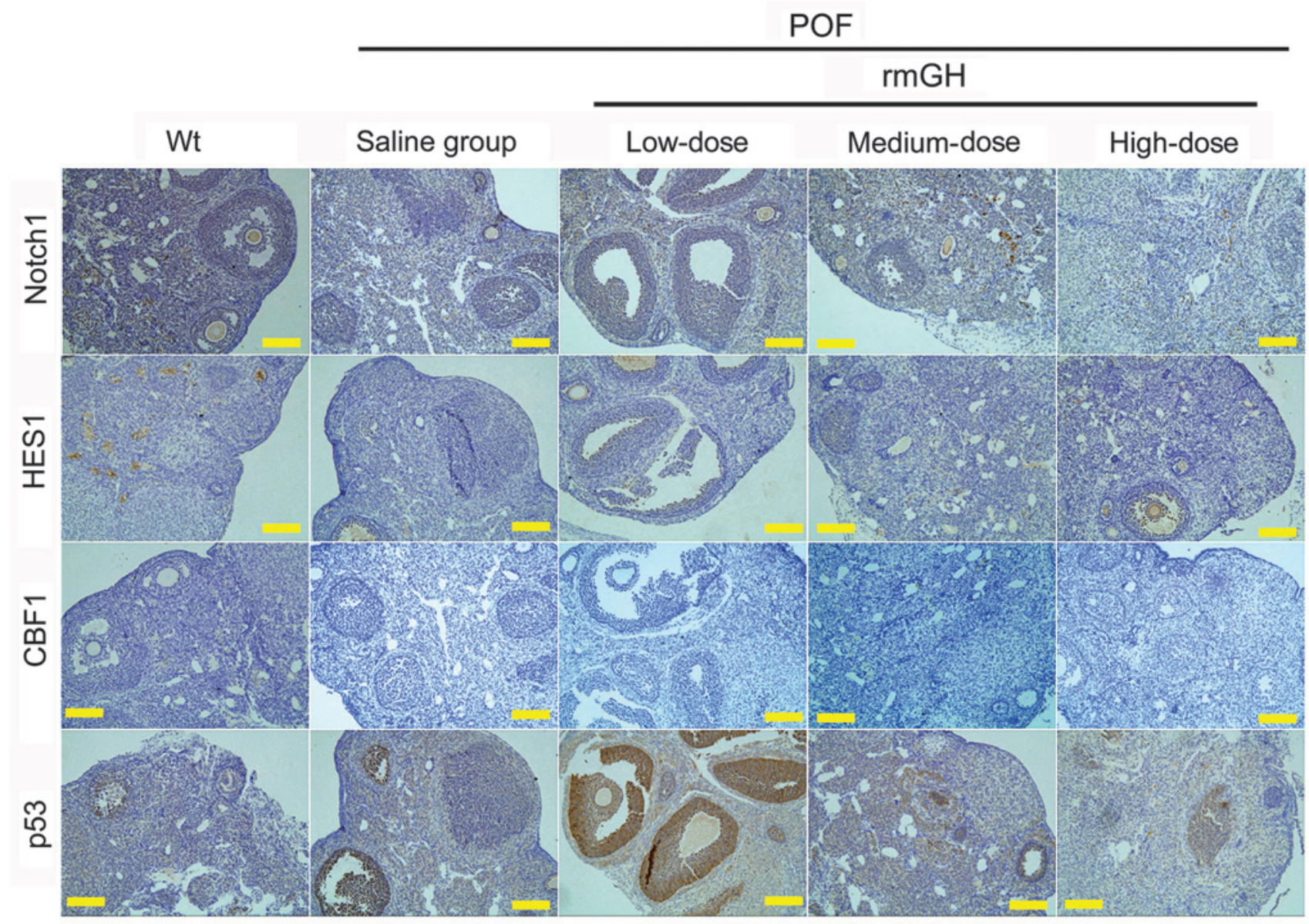

Figure 4. Protein expression of Notch1 signaling pathway factors and p53 using immunohistochemistry. Staining indicated positive or markedly positive staining for Notch1 signaling pathway factors (Notch1, CBF1, and HES1), but not for p53 in the Wt, medium-dose, and high-dose groups, as compared with the low-dose and saline-treated groups. Magnification, x200. Scale bar=200 $\mu \mathrm{m}$. POF, premature ovarian failure model; rmGH, recombinant mouse growth hormone; Wt, wild-type; HES1, hairy/enhancer of split.

POF mice treated with medium and high doses of rmGH. Oocyte maturation is closely associated with several factors, including the ovarian microenvironment, the extent of development of the ovarian corpus luteum, the activity of ovarian granulosa cells, hormone release and endocrine regulation (1-5). The results of the current study confirm that GH may effectively treat multiple features of POF in mice displaying disease symptoms.

The novel evidence that $\mathrm{GH}$ regulates the expression of Notch-1 signaling pathway genes in ovarian tissue from POF mice in order to induce regeneration and repair was also presented. The Notch-1 signaling pathway is known to regulate cell proliferation and tumorigenesis but, to the best of our knowledge, it has not previously been associated with POF. In the current study, Notch-1 signaling pathway genes were expressed at different levels when POF mice were treated with varying concentrations of GH. For example, a medium dose of rmGH caused the greatest activation of Notch-1 signaling pathway genes in the ovarian tissue of POF mice. The hypothesized role of the Notch pathway genes based on the current model suggests that the direct effect of Notch-1 signaling pathway activation is the proliferation of ovarian cells to restore function, and thus, repair and replace damaged ovarian cells in the POF mouse model. It is therefore hypothesized that $\mathrm{GH}$ was activated through the expression of the Notch-1 pathway in ovarian cells to repair ovarian function.

In conclusion, the results of the present study suggest that $\mathrm{GH}$ promotes ovarian tissue repair and regeneration, estrogen release and oocyte maturation by activating the expression of Notch-1 signaling pathway factors in the ovarian tissue of mice exhibiting POF.

\section{Acknowledgements}

The present study was supported by the National Natural Science Foundation of China (grant no. 81273794), the National Natural Science Foundation of China (grant no. 81202811), and the China Postdoctoral Science Foundation (grant nos. 2014M550250 and 2015T80455).

\section{References}

1. Bandyopadhyay S, Chakrabarti J, Banerjee S, Pal AK, Goswami SK, Chakravarty BN and Kabir SN: Galactose toxicity in the rat as a model for premature ovarian failure: An experimental approach readdressed. Hum Reprod 18: 2031-2038, 2003.

2. Beck-Peccoz P and Persani L: Premature ovarian failure. Orphanet J Rare Dis 1: 9, 2006.

3. Persani L, Rossetti R and Cacciatore C: Genes involved in human premature ovarian failure. J Mol Endocrinol 45: 257-279, 2010. 
4. McGuire MM, Bowden W, Engel NJ, Ahn HW, Kovanci E and Rajkovic A: Genomic analysis using high-resolution single-nucleotide polymorphism arrays reveals novel microdeletions associated with premature ovarian failure. Fertil Steril 95 : 1595-1600, 2011

5. Vujović S, Ivović M, Tancić-Gajić M, Marina L, Barać M, Arizanorić Z, Nenezić A, Ivaniserić M, Micić J, Sajić S and Micić D: Premature ovarian failure. Srp Arh Celok Lek 140: 806-811, 2012

6. Qin Y, Sun M, You L, Wei D, Sun J, Liang X, Zhang B, Jiang H, $\mathrm{Xu} \mathrm{J}$ and Chen ZJ: ESR1, HK3 and BRSK1 gene variants are associated with both age at natural menopause and premature ovarian failure. Orphanet J Rare Dis 7: 5, 2012.

7. Rebar RW: Premature ovarian 'failure' in the adolescent. Ann N Y Acad Sci 1135: 138-145, 2008.

8. Kalantari H, Madani T, Zari Moradi S, Mansouri Z, Almadani N, Gourabi $\mathrm{H}$ and Mohseni Meybodi A: Cytogenetic analysis of 179 Iranian women with premature ovarian failure. Gynecol Endocrinol 29: 588-591, 2013.

9. Duncan M, Cummings L and Chada K: Germ cell deficient (gcd) mouse as a model of premature ovarian failure. Biol Reprod 49: 221-227, 1993

10. Cecchi CR, Higuti E, Oliveira NA, Lima ER, Jakobsen M, Dagnaes-Hansen F, Gissel H, Aagaard L, Jensen TG, Jorge AA, et al: A novel homologous model for gene therapy of dwarfism by non-viral transfer of the mouse growth hormone gene into immunocompetent dwarf mice. Curr Gene Ther 14: 44-51, 2014.

11. Visser JA, Hokken-Koelega AC, Zandwijken GR, Limacher A, Ranke MB and Flück CE: Anti-Müllerian hormone levels in girls and adolescents with Turner syndrome are related to karyotype, pubertal development and growth hormone treatment. Hum Reprod 28: 1899-1907, 2013.

12. Hartmann BW, Kirchengast S, Albrecht A, Huber JC and Söregi G: Effect of hormone replacement therapy on growth hormone stimulation in women with premature ovarian failure. Fertil Steril 68: 103-107, 1997.

13. Kopchick JJ, List EO, Kelder B, Gosney ES and Berryman DE: Evaluation of growth hormone $(\mathrm{GH})$ action in mice: Discovery of GH receptor antagonists and clinical indications. Mol Cell Endocrinol 386: 34-45, 2014.

14. Rojanathammanee L, Rakoczy S and Brown-Borg HM: Growth hormone alters the glutathione $\mathrm{S}$-transferase and mitochondrial thioredoxin systems in long-living Ames dwarf mice. J Gerontol A Biol Sci Med Sci 69: 1199-1211, 2014.
15. Chesnokova V, Zhou C, Ben-Shlomo A, Zonis S, Tani Y, Ren SG and Melmed S: Growth hormone is a cellular senescence target in pituitary and nonpituitary cells. Proc Natl Acad Sci USA 110: E3331-E3339, 2013.

16. Villares R, Kakabadse D, Juarranz Y, Gomariz RP, Martínez-AC and Mellado M: Growth hormone prevents the development of autoimmune diabetes. Proc Natl Acad Sci USA 110: E4619-E4627, 2013

17. Subramaniam D, Ponnurangam S, Ramamoorthy P, Standing D, Battafarano RJ, Anant S and Sharma P: Curcumin induces cell death in esophageal cancer cells through modulating Notch signaling. PLoS One 7: e30590, 2012.

18. Yao L, Kan EM, Kaur C, Dheen ST, Hao A, Lu J and Ling EA: Notch-1 signaling regulates microglia activation via $N F-\kappa B$ pathway after hypoxic exposure in vivo and in vitro. PLoS One 8: e78439, 2013

19. Ji X, Wang Z, Geamanu A, Goja A, Sarkar FH and Gupta SV: Delta-tocotrienol suppresses notch-1 pathway by upregulating miR-34a in nonsmall cell lung cancer cells. Int J Cancer 131: 2668-2677, 2012.

20. Zhang H, Hilton MJ, Anolik JH, Welle SL, Zhao C, Yao Z, Li X, Wang Z, Boyce BF and Xing L: NOTCH inhibits osteoblast formation in inflammatory arthritis via noncanonical $\mathrm{NF}-\kappa \mathrm{B}$. J Clin Invest 124: 3200-3214, 2014.

21. Chen G, Qiu Y, Sun L, Yu M, Wang W, Xiao W, Yang Y, Liu Y, Yang S, Teitelbaum DH, et al: The Jagged-2/Notch-1/Hes-1 pathway is involved in intestinal epithelium regeneration after intestinal ischemia-reperfusion injury. PLoS One 8: e76274, 2013.

22. Wang Z, Azmi AS, Ahmad A, Banerjee S, Wang S, Sarkar FH and Mohammad RM: TW-37, a small-molecule inhibitor of $\mathrm{Bcl}-2$, inhibits cell growth and induces apoptosis in pancreatic cancer: Involvement of Notch-1 signaling pathway. Cancer Res 69: 2757-2765, 2009.

23. Liu T, Huang Y, Zhang J, Qin W, Chi H, Chen J, Yu Z and Chen C: Transplantation of human menstrual blood stem cells to treat premature ovarian failure in mouse model. Stem Cells Dev 23: 1548-1557, 2014.

24. Livak KJ and Schmittgen TD: Analysis of relative gene expression data using real-time quantitative PCR and the 2(-delta delta C(T)) method. Methods 25: 402-408, 2001.

25. Shen DZ, Xin SL, Chen C and Liu T: Effect of atorvastatin on expression of TLR4 and NF- $\mathrm{B}$ p 65 in atherosclerotic rabbits. Asian Pac J Trop Med 6: 493-496, 2013. 